\title{
The life cycle of the Atlantic Beach-Cricket, Pseudomogoplistes vicentae Gorochov, 1996
}

\author{
Karim Vahed ${ }^{1}$ (1)
}

Received: 19 June 2019 / Accepted: 20 October 2019 / Published online: 5 November 2019

(c) The Author(s) 2019

\begin{abstract}
The Atlantic Beach-Cricket, Pseudomogoplistes vicentae, inhabits shingle beaches, with a range that extends from the UK to the Canary Islands. Little is known about the natural history of this species, which is listed by the IUCN as Vulnerable. In the present study, a combination of field sampling (by pitfall trapping and direct searching) in spring, summer, autumn and late winter at two different sites in the UK, together with culturing eggs and nymphs in captivity, was used to determine the life cycle. Eggs laid in August in captivity showed no visible embryonic development until May and hatched the following July. There was no difference in the time taken to hatch between eggs maintained over winter at either 4 or $11^{\circ} \mathrm{C}$. Nymphal instars present in the field indicated that the majority of eggs hatch from June to early August. From October to February in the field, the majority of nymphs were estimated to be at the 7th instar. Development appeared to resume by April and nymphs reached adulthood by July to August in the field, two years after the eggs from which they hatched were likely to have been laid. The number of nymphal instars ranged from 10 to 11 (mode: 11) in males and 11 to 13 (mode: 12) in females. In captivity, most adult males died by the end of November, while 35\% of females survived until March. Females preferred to oviposit in driftwood rather than in sand in the laboratory. This fact, together with the early embryonic diapause, suggests that the species might be able to disperse by rafting at the egg stage.
\end{abstract}

Keywords Orthoptera $\cdot$ Mogoplistidae $\cdot$ Sex-ratio $\cdot$ Instars $\cdot$ Diapause $\cdot$ Oviposition $\cdot$ Scaly cricket

\section{Introduction}

In comparison with other species of cricket that occur in Western Europe, little is known about the natural history of the Atlantic Beach-Cricket, or Scaly Cricket, Pseudomogoplistes vicentae (Mogoplistidae) (Sutton 2015; Fig. 1). Knowledge of the life cycle of this species, which is listed as 'Vulnerable' by the IUCN (Sutton 2015; Sutton et al. 2017; Hochkirch et al. 2016a, b), is currently incomplete (Timmins 1994a, b; Sutton 1999; Livory et al. 2000; Benton 2012). Members of the genus Pseudomogoplistes are highly unusual for crickets in that they occur very close to the sea,

Electronic supplementary material The online version of this article (https://doi.org/10.1007/s10841-019-00187-1) contains supplementary material, which is available to authorized users.

Karim Vahed

K.Vahed@Derby.ac.uk

1 School of Environmental Sciences, Environmental Sustainability Research Centre, University of Derby, Kedleston Road, Derby DE22 1GB, UK under cobbles and amongst shingle near to the upper strand line (Sutton 1999, 2015; Benton 2012; Dusoulier 2017). P. vicentae is known to occur in small and apparently isolated populations in four places in the U.K. (Branscombe, Devon, Marloes sands and Dale beaches, Pembrokeshire and Chesil Beach, Dorset), the Channel Islands (Sark and Guernsey), France (Brittany and Normandy), the Atlantic coast of Spain, Portugal, Morocco, Algeria (Habibas Islands) and the Canary Islands (Gorochov 1996; Sutton 1999, 2015; Sutton et al. 2017; Morère and Livory 1999; Livory et al. 2000; Sahnoun et al. 2010; Benton 2012; Hochkirch et al. 2016a, b; Kleukers et al. 2018). Where the species does occur, the populations tend to be found within very restricted areas of suitable habitat (Timmins 1994b; Sutton 1999, 2015; Sutton et al. 2017; Hudson 2006; Gardiner 2009). Potential threats to the survival of populations include an increase in the frequency of severe weather events and rising sea levels associated with climate change, together with marine pollution events (Sutton 2015; Sutton et al. 2017; Hochkirch et al. 2016a, b). 


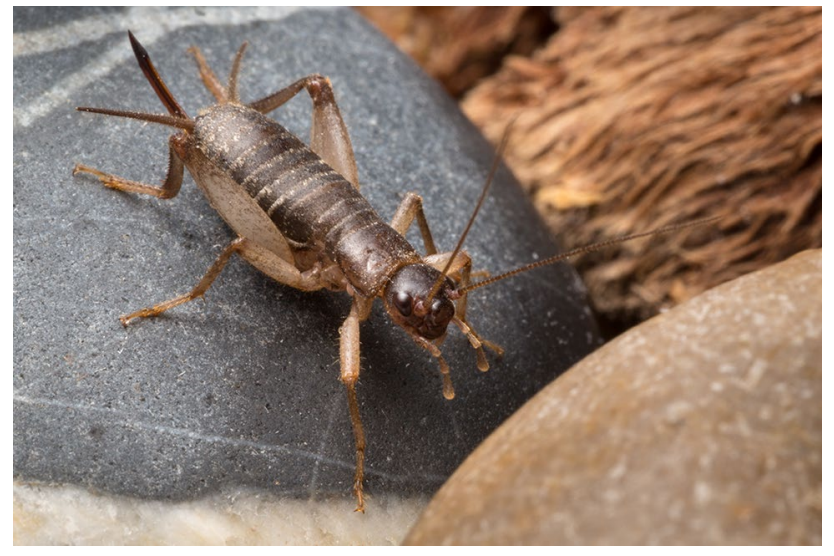

Fig. 1 An adult female P. vicentae. Photograph by Alex Hyde

Crickets and relatives (Orthoptera: Ensifera) exhibit a wide variety of different life cycles. At least nine distinct types of life cycle are known to occur in the Grylloidea (Masaki 1996; Masaki and Walker 1987). In most species, the winter in temperate zones is passed in the egg stage, in others the nymph stage, and in a few species, the adult stage (reviewed in Masaki and Walker 1987). The life cycle for each species is not fixed, however, and variation can occur between different populations (Brown 1978; Masaki and Walker 1987; Masaki 1996). In some species of True Crickets (Grylloidea) in Northern Europe, such as the Field Cricket (Gryllus campestris, Gryllidae) and the Mole Cricket (Gryllotalpa gryllotalpa, Gryllotalpidae), the eggs take only 2-4 weeks to hatch and the following winter is passed as large nymphs (Ismail and Fuzeau-Braesch 1976; Pearce-Kelly et al. 1997; Benton 2012). The wood cricket (Nemobius sylvestris (Bosc.), Gryllidae), on the other hand, has a life cycle that includes two to three winters. The first winter is spent in the egg stage and the second as intermediate-sized nymphs. These reach adulthood by mid-summer and some of these adults may also survive a third winter (Gabbutt 1959; Brown 1978).

It has been proposed that the life cycle of $P$. vicentae in the U.K. and France spans 2 to 3 years, based on the presence of adults and first instar nymphs in July and August and the occurrence of larger nymphs (and adults) in both the early autumn and early spring (Timmins 1994b; Sutton 1999; Livory et al. 2000). Sutton (1999) presented three alternative versions of the life cycle of this species that could account for these patterns, all of which involved overwintering at the nymphal stage. The number of nymphal instars, or the precise nymphal instar/s which overwinter, has not been determined previously, however (Sutton 1999; Benton 2012). It has been proposed that the eggs may also overwinter (Sutton 1999; Livory et al. 2000, but see Timmins 1994b), although the development of the eggs has not previously been studied. While the presence of both first instar nymphs and adults in the summer (Sutton 1999; Livory et al. 2000) could indicate that the eggs have overwintered and have taken nearly a year to hatch, this observation could also be consistent with eggs that hatch within a few weeks of laying. Timmins (1994b) reported the discovery of an adult female $P$. vicentae in April at the Chesil beach site and proposed that it is probably therefore fertilised adult females, rather than the eggs, that overwinter.

Where female $P$. vicentae lay their eggs is also uncertain. Observations of a few captive individuals have suggested that they may oviposit in or on damp sand (Paul 1987; Benton 2012). The shape of the female's ovipositor in ensiferans may give some indication of the favoured oviposition medium (Gwynne 2001). Relatively stout, broad and up-curved ovipositors, for example, occur in species such as Pholidoptera griseoaptera and Conocephalus dorsalis that are known to oviposit in dead wood and plant stems, respectively (Benton 2012). By contrast, species of ensiferan that lay in soil or sand, such as G. campestris, often have relatively long, slender and straight ovipositors (Gwynne 2001; Benton 2012). In P. vicentae, the ovipositor is relatively short, wide and slightly curved (Fig. 1), suggesting that it might lay eggs in fibrous plant material. One potential source of such material in the species' habitat is driftwood. Oviposition in dead wood has been recorded in the North American mogoplistine Cycloptilum hesperum (Love and Walker 1979).

Previous field surveys of populations of $P$. vicentae in the U.K. have all reported a female-biased adult sex ratio (Kirby 1995, Timmins 1994a, 1996; Sutton 1999; Livory et al. 2000; Hudson 2006). Pickard (1956) even proposed that the species may be parthenogenetic. Exclusively female, parthenogenetic, populations are known to occur in some ensiferan species, such as in certain populations of the European myrmecophilid cricket Myrmecophilus acervorum (Espadaler and Olmo-Vidal 2011). Whether a laboratory reared population of $P$. vicentae would show a female-biased primary adult sex ratio is unknown.

Knowledge of the life cycle and life stage structure of a species of conservation concern is important in order to inform conservation strategies for that species (Mills 2012). The overall aim of the present study was determine the lifecycle of $P$. vicentae, focussing on populations in the U.K. at Branscombe (Devon) and Marloes sands (Pembrokeshire). A combination of field sampling at different times of year and rearing individuals in captivity was used to examine the following: (1) the number of nymphal instars, and when each is present in the field; (2) the adult life-span of males and females (in the lab.); (3) the adult sex ratio of nymphs raised from eggs in the lab.; (4) the preferred medium for oviposition (sand versus driftwood); (5) how long eggs take to show visible embryonic development and to hatch; (6) the effect of 
two different over-winter temperatures on egg development and (7) whether eggs laid by un-fertilised females will hatch.

\section{Methods}

\section{Developmental stages present in the field}

Field sampling of the $P$. vicentae populations was conducted at two separate field locations: East Beach, Branscombe, Devon (grid references: SY21433 88036-SY22532 87916) (see Sutton 1999 for information on previous surveys of this site) and Marloes Sands, Pembrokeshire (grid references: SM78229 07596-SM78724 07254) (see Hudson 2006 for a survey of this site). At the Branscombe site, sampling was conducted on the last week of May (2012, 2015, 2017 and 2018), the last week of July (2012, 2013 and 2014), the last week of August (2016), early September (2015) and the last week of October (2011, 2012 and 2013). The Marloes Sands population was sampled in mid-February (2015 and 2016), late March (2016), mid-April (2017), the last week of May (2014), the last week of July (2015), early August (2016) and the last week of October (2014, 2015 and 2016). Exact sampling dates and grid references are provided in Table S1 (Electronic Supplementary Material).

At both sites, the south-facing beach was backed by cliffs (of Silurian sandstone and shales at Marloes and Cretaceous limestone and chalk at Branscombe), which were predominantly sheer, but were intersected by less steep, vegetated areas. At Marloes sands, $P$. vicentae occurred relatively close to the cliffs in banks of large pebbles and cobbles, which were fronted by a sandy beach at low tide (Hudson 2006). Many of the large cobbles at the seaward edge of the deposit lay directly on the sand. It was therefore possible to collect individuals by simply turning over flat cobbles and large pebbles within and around the edge of the storm deposit (as recommended by Hudson 2006), using an aspirator to pick up small nymphs. The duration of hand searches ranged from 15 to $120 \mathrm{~min}$ (see Table S1, Electronic Supplementary Material). Pitfall traps were also used (see below). At the Branscombe site however, the shingle consisted of a much more uniform layer of pebbles which covered most of the beach. It was not possible to search for the crickets by turning over stones, not only because the stones were smaller, but also because of the depth of the shingle; scaly crickets were easily able to escape by climbing deeper into the shingle. Only pitfall traps were therefore used at this site (following Timmins 1996).

On each sampling event, between 4 and 33 pitfall traps were set up, spaced at least $2 \mathrm{~m}$ apart (see Table $\mathrm{S} 1$ for the number of traps in each sampling event). These were mainly positioned along the upper strand line, but some were also located closer to the cliffs. Each pitfall trap consisted of a plastic pint cup, which was dug into the shingle so that its top was level with the top of the shingle. To do this, a crater was dug into the shingle using a stick, then two plastic cups, one inside the other, were positioned within the depression, after which the shingle was back-filled. The inner cup was then removed (this avoided loose shingle from the back-fill getting into the trap). Traps were baited with cat biscuits ('Go-Cat', tuna and herring flavour, Purina), together with scraps of seafood (cooked prawn heads, white bait or sea bream). Baiting of traps has been found to attract more scaly crickets (Timmins 1996). To keep out rain and gulls, the top of each trap was then covered by a large stone, supported by four pebbles to leave a gap to allow the crickets to enter the trap. A pebble and fragments of seaweed or driftwood were also placed within the trap to provide refuges for the crickets. Trapping was generally only conducted on dry nights. Traps were set up in the evening, just before sunset and were checked early the next morning, after which they were removed.

All nymphs caught (by pitfall trapping or hand searching) were photographed with either a digital camera (Panasonic Lumix DMC-TZ18) or using an i-Phone camera (i-Phone 4s). The programme Image-J (Schneider et al. 2012) was later used to take measurements of head width, from the outside of each eye. The instar was estimated by comparing this value with the mean derived from photographs of known instars from lab-raised individuals $(\mathrm{n}=10$ for each instar, see below). An overall visual comparison was also made between the image of the field-collected nymph in question and those of lab-reared nymphs of known instars, taking into account further features such as pronotum width and body length, together with antenna and cerci length, where these did not appear to be broken. Photographs were taken at a set distance by placing the nymph/s in a colourless polythene specimen pot (diameter $47 \mathrm{~mm}$, height $72 \mathrm{~mm}$ ), and resting the camera on the open end of the container. A $1 \mathrm{~cm}$ rule, marked in $0.1 \mathrm{~mm}$ divisions, was placed in the bottom of the container. Nymphs were then released close to where they were caught.

\section{Lab. studies of nymphal development}

Nymphal development was studied in the lab. primarily using nymphs hatched from eggs laid in captivity (see below), but also with 15 nymphs collected at instar VII from Marloes Sands (in October 2014 and February 2015), 5 male and 6 female nymphs collected at the Xth instar from Marloes Sands in May 2014 and 2 male (Xth and XIth instar) and 2 female (IXth and Xth instar) nymphs collected from Branscombe in May 2018.

Nymphs were maintained in Perspex terraria $(28 \times 13 \times 22 \mathrm{~cm})$ containing half-sections of short card tubes (measuring $10.5 \mathrm{~cm}$ long) which had been cut lengthways, 
and sections of card egg boxes, together with clumps of dried seaweed (Fucus vesiculosus) for shelter, moulting platforms and to increase the surface area. For early instars, approximately 40 nymphs were maintained per cage, but this was reduced to 10 to 20 per cage for mid-stage nymphs. The terraria were fitted with well-ventilated plastic lids. A waterfilled plastic specimen tube ( $1.4 \mathrm{~cm}$ in diameter), stoppered with cotton wool was placed in each cage as a water source. Cages were also mist sprayed with water every morning. Crushed rabbit food pellets (Dodson and Horrell) were provided as a food source and were replenished each week, together with occasional scraps of cooked fish. The terraria were maintained at a natural light-dark cycle (mirroring that in the field) and were exposed to a mean temperature of $24{ }^{\circ} \mathrm{C}$ from June to the end of October. After this, the nymphs were exposed to lower mean temperatures as follows: $11{ }^{\circ} \mathrm{C}$ from November to the end of February; $12{ }^{\circ} \mathrm{C}$ in March and $15{ }^{\circ} \mathrm{C}$ in April. The cages were returned to a temperature of $24{ }^{\circ} \mathrm{C}$ from May.

Nymphs within each cage were inspected at regular intervals (at least every 2 days). When a nymph moulted to the next instar, it was photographed (using the same method as in the field), until at least ten of each instar had been photographed. Using the programme Image-J (Schneider et al. 2012), the head width (at its widest point, from the outer edge of each eye) of ten individuals of each instar was measured from the digital photographs. Newly moulted individuals were easy to detect. This was due to their less distended abdomens, greater head width and antenna and cerci lengths. Furthermore, prior to a moult, individuals became more straw-coloured as their abdomens distended and the density of scales was reduced. Recently moulted individuals, on the other hand, were much darker in body colouration, apparently due to the greater density of scales (the antennae and ovipositor, however, were initially pale in colour following the moult). The shed skins were also rarely eaten.

\section{Adult lifespan (in the lab.)}

In order to compare the life span of male and female $P$. vicentae, seventeen adult males and an equal number of adult females were maintained in single-sex terraria (in three separate terraria per sex, each measuring $28 \times 13 \times 22 \mathrm{~cm}$ ) in conditions similar to those described for the nymphs (above). The cages were checked at least once per week from 3rd August 2014 over a year and the number of surviving individuals was recorded.

These individuals consisted of five males and six females collected from Marloes sands as Xth instar nymphs in the last week of May 2014 (which became adult from 15th to 26th July 2014, see results section), plus twelve males and eleven females collected as adults from the field at the Branscombe study site on 30th July 2014. Note that from 30th July to 18th August, sexes were maintained together for 20 days (keeping individuals from the two collecting sites separate) in order to gather fertile eggs (see below), after which they were returned to single-sex tanks.

\section{Choice of oviposition site}

As a preliminary test of whether female $P$. vicentae prefer to lay eggs in damp sand or in driftwood, a choice of these substrata were provided within a terrarium containing eleven adult females from the Branscombe population (see above). A layer of fine damp sand, approximately $20 \mathrm{~mm}$ deep, with a surface area of $20 \mathrm{~cm}^{2}$ was placed in one corner of the terrarium, while two pieces of soft driftwood with a similar surface area were placed in the opposite corner of the tank. For 14 days, from 20th September 2014, the terrarium was observed at $10 \mathrm{pm}$ and the number of females ovipositing on each of the two substrata was recorded.

\section{Egg development}

Eleven females from the Branscombe population were maintained from 30th July to 18th August (20 days) with 10 males from the same site in a terrarium containing 11 damp cotton-wool discs (make-up removal pads, $6 \mathrm{~cm}$ in diameter) in which to lay eggs. A total of 440 eggs were laid within the cotton wool discs (which were then removed for incubation) during this period.

Eggs were removed with forceps from the cottonwool pads in which they were laid. The pads consisted of layers which could be separated to facilitate removing eggs. The eggs were placed within petri dishes $(9 \mathrm{~cm}$ in diameter and $1.5 \mathrm{~cm}$ deep), up to 40 per petri dish, in rows on top of pads of cotton wool $(6 \mathrm{~cm}$ in diameter and approximately $8 \mathrm{~mm}$ deep). These were kept damp to the touch and were never allowed to dry out. The eggs were inspected every few days and any eggs which had begun to decay were removed and recorded. The petri dishes were kept in batches of four within colourless perspex boxes $(15 \times 10.5 \times 7.5 \mathrm{~cm})$ in which a series of holes had been made for ventilation. The eggs were exposed to natural day-length (apart from in the cool treatment in treatment B, see below) and a sample of eggs were exposed to two main treatments to examine the effect of two different overwintering temperatures $\left(11^{\circ} \mathrm{C}\right.$ versus $\left.4{ }^{\circ} \mathrm{C}\right)$ on egg development. In Treatment A $(n=182)$, eggs were maintained at a mean temperature of $24{ }^{\circ} \mathrm{C}$ until 24th October 2014, after which they were moved to a mean temperature of $11{ }^{\circ} \mathrm{C}$ until 3rd March 2015. In Treatment B $(n=149)$, eggs were also maintained at a mean temperature of $24{ }^{\circ} \mathrm{C}$ until 24th October 2014, after which they were moved to a mean temperature of $11^{\circ} \mathrm{C}$ until 23rd December 2014. They were then placed in a refrigerator (in the dark) at a 
mean temperature of $4{ }^{\circ} \mathrm{C}$ until 3rd March (70 days). From 3rd March 2015, eggs in both Treatments A and B were moved to higher temperatures as follows: mean $12^{\circ} \mathrm{C}$ for the remainder of March; mean $15^{\circ} \mathrm{C}$ in April and $16^{\circ} \mathrm{C}$ in May and early June. On 15th June 2015 eggs in both treatments were exposed to a mean temperature $24^{\circ} \mathrm{C}$ until hatching occurred.

The developmental stage of the embryos within a sample of randomly chosen eggs (from a variety of petri dishes) was assessed on 23rd December 2014 (20 eggs per treatment), 3rd March 2015 (10 eggs per treatment) and 20th May 2015 (20 eggs per treatment). If eggs were damp, the chorion of the egg was transparent and the development of the embryo within was easy to assess, by placing the egg in a petri dish of distilled water and viewing it under a dissecting microscope. If the surface of the egg had dried, however, the chorion tended to become opaque and would not always become transparent again even if soaked in water. In the December and March samples, a method developed by Groepler (1981) was used to clarify the chorion. The disadvantage of this method was that it involved destructive sampling (of $30 \mathrm{eggs}$ in each treatment). In the May sampling, only damp eggs were examined in order to avoid this.

The stages of embryonic development of eggs within each sample were noted, following Brookes (1952) and Hartley (1990). Easily recognisable stages of embryonic development include: yolk blocking, which occurs in viable, fertilised eggs (Hartley and Warne 1972), anatrepsis, in which the embryo grows towards the posterior pole of the egg (and segmentation and limb buds develop) and katatrepsis (or rotation), in which the embryo rotates forward around the posterior pole of the egg and begins to grow towards the anterior pole (Hartley 1990). This is followed by "dorsal closure", in which the embryo grows around and encloses the yolk and "completion", in which the limbs become fully developed and pigmentation develops (Hartley 1990). At dorsal closure and completion, the dark eye-spots are clearly visible through the chorion at the anterior end of the egg, even in eggs in which the chorion has not been clarified. When hatching began, eggs were checked every day and newly hatched nymphs were counted and removed from each petri dish using an aspirator and were transferred to the rearing cages.

In order to assess whether un-fertilised eggs would hatch, seven adult virgin females (five from Marloes Sands and two from Branscombe), which were collected in the field as nymphs, were maintained separately in terraria (as outlined in the 'lab.studies of nymphal development' methods, above) for 3 months (from August to October). Cages were provided with damp cotton-wool discs $(6 \mathrm{~cm}$ in diameter) as an oviposition substrate.

\section{Results}

\section{Developmental stages present in the field}

The number of individuals of each instar (and of each sex, in the case of imagoes) found in the field at Branscombe, Devon and at Marloes Sands, Pembrokeshire are shown in Table 1. The patterns found were very similar at both sites:

\section{Summer}

In late July (both sites) and early August (Marloes Sands), a mix of Ist to IVth instar nymphs were found, together with adults (plus a final instar nymph, in the case of the Marloes site). In late August 2016 (Branscombe site), most nymphs were estimated to be at instar VII to VIII and adults of both sexes were present (Table 1).

\section{Autumn}

In late October, at the start of the overwintering period, the majority of nymphs were estimated to be at instar VII at both sites (with a range from instar III-VII). Adults of both sexes were also present (Table 1).

\section{Winter}

In the two mid-February searches at the Marloes site, the majority of nymphs were estimated to be at instar VII (with a range from instar V to VII) (Table 1). No adults were found in the winter surveys.

\section{Spring}

In late March and mid-April (Marloes site), the majority of nymphs were in the VIIIth instar (with a range of IIIrd-VIIIth instar). In late May, all nymphs at the Marloes site were estimated to be at instar X. The pattern in May was similar at Branscombe, with the majority of nymphs being at either instar X or XI (Table 1). No adults were found in the spring surveys.

\section{Other field observations}

On August 3rd 2016, at the Marloes sands site (SM78404 07486), the shingle beach was observed during an incoming tide, from $1 \mathrm{~h}$ to $30 \mathrm{~min}$ prior to high tide, during high wind and high surf. As the waves advanced up the beach, large swarms of sand-hoppers (Crustacea: Talitridae) were observed hopping up the beach away from the sea. On rocks at the base of the cliffs, approximately one hundred $P$. 
Table 1 The number of individuals at each estimated instar, together with the number of adult males and females, in the field at different times of the year at the study sites in (A) Branscombe, Devon and (B) Marloes Sands, Pembrokeshire ( $p$ pitfall trap; $h$ hand searches)

\begin{tabular}{|c|c|c|c|c|c|c|c|c|c|c|c|c|c|}
\hline & \multicolumn{13}{|c|}{ Estimated instar } \\
\hline & \multirow[t]{2}{*}{ I } & \multirow[t]{2}{*}{ II } & \multirow[t]{2}{*}{ III } & \multirow[t]{2}{*}{ IV } & \multirow[t]{2}{*}{$\mathrm{V}$} & \multirow[t]{2}{*}{ VI } & \multirow[t]{2}{*}{ VII } & \multirow[t]{2}{*}{ VIII } & \multirow[t]{2}{*}{ IX } & \multirow[t]{2}{*}{$X$} & \multirow[t]{2}{*}{ XI } & \multicolumn{2}{|l|}{ Adult } \\
\hline & & & & & & & & & & & & Male & Female \\
\hline \multicolumn{14}{|l|}{ (A) Branscombe, Devon. } \\
\hline Late May $(2012,2017,2018)(p)$ & 0 & 0 & 0 & 0 & 0 & 0 & 0 & 2 & 0 & 5 & 5 & 0 & 0 \\
\hline Late July $(2012,2013,2014)(p)$ & 7 & 5 & 3 & 0 & 0 & 0 & 0 & 0 & 0 & 0 & 0 & 11 & 43 \\
\hline Late August (2016) (p) & 0 & 2 & 0 & 0 & 0 & 0 & 10 & 6 & 3 & 0 & 0 & 6 & 10 \\
\hline \multirow[t]{4}{*}{ Late October $(2011,2012,2013)(\mathrm{p})$} & 0 & 0 & 0 & 0 & 0 & 4 & 6 & 0 & 0 & 0 & 0 & 6 & 4 \\
\hline & \multicolumn{13}{|c|}{ Estimated instar } \\
\hline & \multirow[t]{2}{*}{ I } & \multirow[t]{2}{*}{ II } & \multirow[t]{2}{*}{ III } & \multirow[t]{2}{*}{ IV } & \multirow[t]{2}{*}{$\mathrm{V}$} & \multirow[t]{2}{*}{ VI } & \multirow[t]{2}{*}{ VII } & \multirow[t]{2}{*}{ VIII } & \multirow[t]{2}{*}{ IX } & \multirow[t]{2}{*}{$\mathrm{X}$} & \multirow[t]{2}{*}{ XI } & \multicolumn{2}{|l|}{ Adult } \\
\hline & & & & & & & & & & & & Male & Female \\
\hline \multicolumn{14}{|l|}{ (B) Marloes Sands, Pembrokeshire } \\
\hline Late May (2014) (h) & 0 & 0 & 0 & 0 & 0 & 0 & 0 & 0 & 0 & 18 & 0 & 0 & 0 \\
\hline Late July (2015) (h) & 7 & 15 & 5 & 7 & 0 & 0 & 0 & 0 & 0 & 0 & 1 & 0 & 3 \\
\hline Early August (2016) (h) & 1 & 1 & 7 & 1 & 0 & 0 & 0 & 0 & 0 & 0 & 0 & 2 & 8 \\
\hline Early August (2016) (p) & 69 & 12 & 21 & 24 & 0 & 0 & 0 & 0 & 0 & 0 & 0 & 33 & 8 \\
\hline Late October $(2014+2015)(\mathrm{h})$ & 0 & 0 & 1 & 0 & 0 & 0 & 16 & 0 & 0 & 0 & 0 & 1 & 3 \\
\hline Late October (2016) (p) & 0 & 0 & 0 & 3 & 5 & 7 & 8 & 0 & 0 & 0 & 0 & 1 & 4 \\
\hline Mid-February (2015 + 2016) (h) & 0 & 0 & 0 & 0 & 1 & 3 & 7 & 0 & 0 & 0 & 0 & 0 & 0 \\
\hline Late March (2016) (h) & 0 & 0 & 0 & 0 & 0 & 1 & 1 & 0 & 0 & 0 & 0 & 0 & 0 \\
\hline Mid-April (2017) (p) & 0 & 0 & 1 & 1 & 0 & 2 & 4 & 6 & 0 & 0 & 0 & 0 & 0 \\
\hline
\end{tabular}

Note that although 11 nymphal instars are shown, the actual number in the lab. varied from 10 to 11 for males and 11 to 13 for females

vicentae nymphs (estimated to be at instar I to III) were then observed all walking rapidly away from the sea and scaling the rocks. One nymph climbed to $6 \mathrm{~m}$ above the beach near to a vegetated part of the cliff, where it retreated into a crevice. Others sheltered under cobbles and larger stones on a ledge on rocks $1 \mathrm{~m}$ above the level of the beach.

While the monitoring of the scaly cricket populations was not an aim of the present study, the repeated visits to the same sites revealed the dynamic, shifting nature of the scaly cricket habitat and apparent effects on the abundance of scaly crickets at specific locations. In December and January 2013/14, a series of unusually severe storms caused storm surges along South-West coast of England and Wales. The study sites at Marloes Sands and Branscombe were within the affected area. At the Branscombe site, the storm surge appears to have reached the base of the cliff and a substantial reduction in the depth of the shingle and re-shaping of the beach profile was evident at parts of the study site and adjacent areas. Pitfall trapping in late July 2014 revealed that adults were still present (which would have been over-wintering nymphs when the storm surges hit). No newly hatched nymphs were found, however (in contrast to the previous July) and no larger nymphs were found in pitfall trap surveys the following
April and May (2015, see Electronic supplementary material, Table S1). This suggests that while mid-stage nymphs managed to survive the storm surge, the over-wintering eggs did not.

At the Marloes Sands site, however, the presence of both large nymphs in May 2014 and mid-stage nymphs and adults in October 2014 indicate that both eggs and over-wintering nymphs had survived the storm surges of winter 2013/14. Nevertheless, the dynamic nature of the habitat was still evident. The first study site (at SM78578 07374), which was first sampled in May 2014, consisted of a bank of cobbles and shingle against the base of the cliff in which a dense population of scaly crickets was found (e.g. 18 in a $15 \mathrm{~min}$ search in May 2014, Table S1). Following a series of storms in the autumn and winter of 2015/16, the bank of cobbles was almost completely flattened out and there was evidence (e.g. the presence of decomposing goose-barnacles) that waves had reached the base of the cliff. The number of scaly crickets found dropped dramatically. In October 2014, for example, 17 nymphs and 3 adults had been found in a $1 \mathrm{~h}$ search, while in October 2015 a similar search yielded only one adult (Table S1). Following similarly small catches at the site in February and March 2016, the sampling locality was changed to other parts of the beach (Table S1). 


\section{Lab. studies of nymphal development}

The number of nymphal instars ranged from 10 to 11 $($ mode $=11, n=11)$ in males and $11-13($ mode $=12, n=9)$ in females. The mean head width (from the outer edge of each eye) of each instar in lab.-reared individuals (based on males only from instar X) is shown in Fig. 2. The mean head width did not differ significantly between lab.reared and field collected adult males (mean \pm S.E. for lab. reared males $=2.65 \pm 0.03 \mathrm{~mm}$; mean for field-collected males $=2.62 \pm 0.03 \mathrm{~mm}, t=0.49$, d.f. $=18, P>0.05)$. The mean head width of adult females (mean $=2.93 \pm 0.05 \mathrm{~mm}$ ) was significantly greater than that of adult males (data from field-collected individuals; $t=-4.96, d . f .=18, P<0.001)$. The mean width of the end of the abdomen (from the outer side of the base of each cercus), however, was significantly greater in adult males (mean $=3.7 \pm 0.14 \mathrm{~mm}$ ) than in adult females $($ mean $=2.62 \pm 0.05 \mathrm{~mm} ;=7.25$, d.f. $=18$, $P<0.001)$. In females, the ovipositor was visible from above from two instars before adulthood. The mean \pm S.E. ovipositor length (as viewed from above) was $0.54 \pm 0.05 \mathrm{~mm}$ $(\mathrm{n}=5)$ at two instars prior to adulthood, $1.86 \pm 0.06 \mathrm{~mm}$ $(n=10)$ at one instar before adulthood and $4.23 \pm 0.10 \mathrm{~mm}$ $(\mathrm{n}=10)$ in adults.

By the 30th October 2015, the eggs from the eleven females from Branscombe (which hatched in June-July 2015) had resulted in a total of 249 nymphs, ranging in size from IVth to VIIIth instar (with most in the VIth instar). Following the over-winter treatment (on 25/04/16), this number had reduced to 99 nymphs. Sixty of these nymphs were released into the field in May 2016 at a site adjacent to the Branscombe site, with the permission of Natural England (Vahed, in prep).

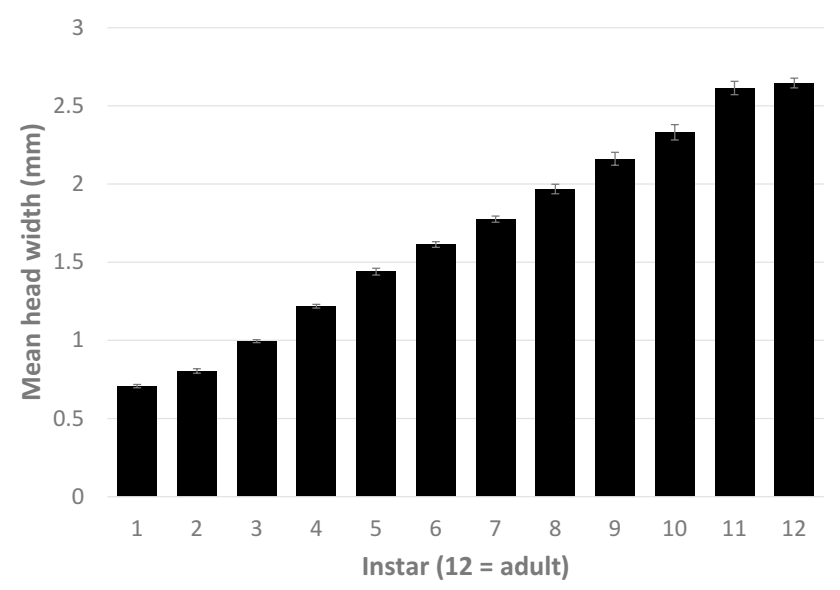

Fig. 2 Mean head width of each instar P. vicentae (with Standard Error bars). Based on lab-reared individuals (using males only from instar X). For simplicity, 11 instars are shown, but the number of instars is variable (see text)
The 15 nymphs collected at instar VII from Marloes Sands (in October 2014 and February 2015) and maintained in captivity resulted in 5 adult males and 5 adult females. The males became adult from 5th to 13th August 2015. The females showed a very similar pattern, becoming adult from 6th to 13th August 2015. In the case of the 5 male and 6 female nymphs collected at the Xth instar from Marloes Sands in May 2014, on the other hand, the males became adult from 15 th to 22 nd July 2014, while the females became adult from 22 nd to 26 th July 2014. The two male nymphs collected from the Branscombe site in May 2018 became adult on 23rd June and 3rd July 2018, while the two female nymphs collected at the same time became adult on the 6 th and 25th July 2018.

\section{Sex ratio in the lab and field}

The adult sex ratio of individuals that had been raised from eggs (from the Bransombe stock) in the lab. was not significantly different from unity (18 males; 14 females; Chi squared $=0.5$, d.f. $=1, P>0.05)$. A significantly femalebiased adult sex ratio was found in late July at the Branscombe site, however (pitfall trap data for 2012-2014 combined: 11 males, 43 females; Chi squared $=18.96$, d.f. $=1$, $P<0.0001)$. The adult sex ratio obtained at Marloes Sands in late July and early August (2015 and 2016, pitfall trap and hand search data combined), on the other hand, was significantly male-biased (35 males, 19 females; Chi squared $=4.74, d . f .=1, P<0.05)$. The number of adults caught in the October surveys at both sites (Table 1) were too small for statistical analysis.

\section{Adult lifespan (in the lab.)}

The percentage of both sexes of adult $P$. vicentae alive each week over the course of a year (from 3rd August 2014) is shown in Fig. 3. Kaplan-Meier survival analysis revealed that there was a significant difference in the survivorship of males and females (Log Rank statistic $=28.59$, $P<0.0001)$ : the mean $( \pm$ S.E. $)$ survival time of adult males was $15.2 \pm 0.6$ weeks, while that of adult females was $29.1 \pm 2.1$ weeks. Most of the males died during November 2014, with none surviving beyond the first week of December 2014 (Fig. 3). Six of the 17 females (35\%), on the other hand, survived to the following spring (March 2015) and one of these survived until the first week of July 2015.

\section{Choice of oviposition site}

Over 14 nights, a mode of 2 females (range 1-4) were observed ovipositing in the driftwood per night (Fig. 4), while no females were observed ovipositing in the damp sand during this period. One female was observed laying 


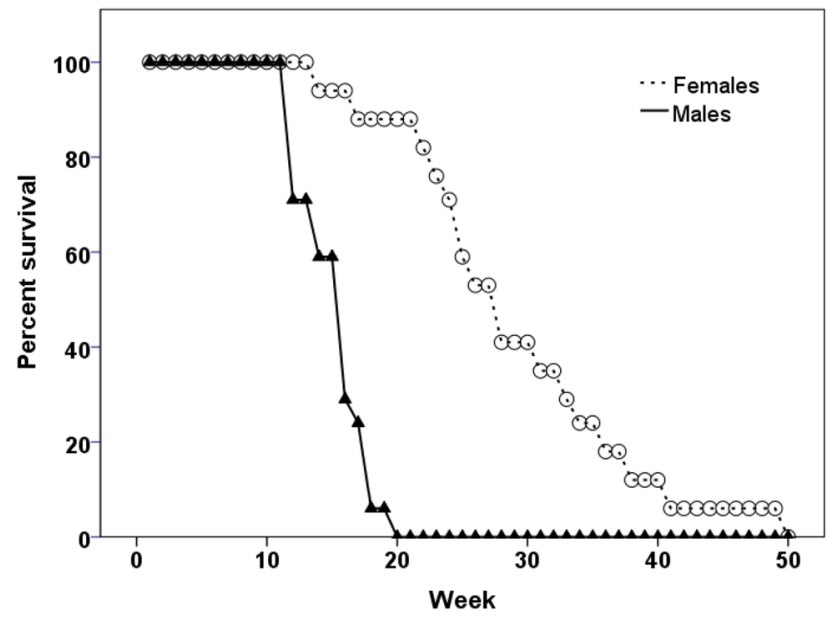

Fig. 3 The percentage of adult male (solid triangles) and female (open circles) alive each week from 3rd August in the lab. (starting with 17 of each sex)

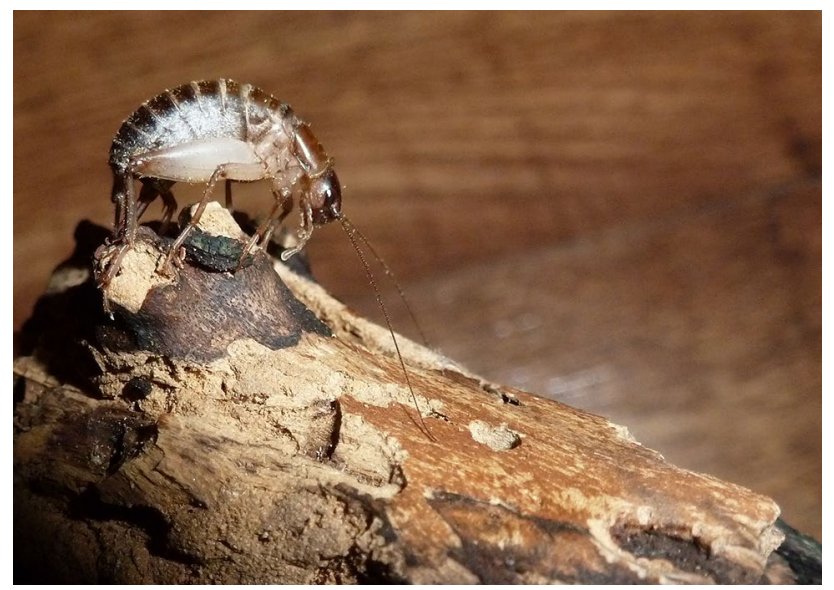

Fig. 4 P. vicentae ovipositing in driftwood. Photograph by K. Vahed

an egg in the damp sand, however, after the 14 day experimental period. Twenty-four weeks after the introduction of the sand, it was sieved, revealing only seven eggs. Over 100 eggs were laid in the driftwood (see Electronic Supplementary Material, Fig. S1), but the exact number was not determined because of difficulty in extracting the eggs without damaging them.

Within the same terrarium, eggs were also laid in other substrata. Eighty-four eggs were laid in a section of card tube, which had been provided as a shelter (measuring $6.5 \times 10 \mathrm{~cm}$ and approximately $1 \mathrm{~mm}$ thick). The eggs had been inserted individually all over the card, between the layers of card. Eggs were also laid in cotton-wool pads within the terrarium.

\section{Egg development}

The samples of eggs from both overwinter temperature treatments $\left(4{ }^{\circ} \mathrm{C}\right.$ and $\left.11{ }^{\circ} \mathrm{C}\right)$ that were assessed on $23 \mathrm{rd}$ December 2014 and on 3rd March 2015 showed no visible signs of embryonic development. All eggs were at the yolk-blocking stage. This suggests that there is an initial diapause, with no visible embryonic development occurring until after the cooling period.

The eggs that were assessed on 20th May 2015, however did show embryonic development. In Treatment A (overwintered at $1{ }^{\circ} \mathrm{C}$ ), 18 of the 20 eggs examined contained embryos in anatrepsis, one in the early stages of katatrepsis and one showed no development beyond yolk-blocking. In treatment $\mathrm{B}$ (overwintered at $4{ }^{\circ} \mathrm{C}$ ), the proportions were similar, with 12 embryos in anatrepsis, six in early katatrepsis and two showing no development beyond yolk-blocking.

The eggs in Treatments A and B hatched from 2nd to 15 th July 2015 . There was no significant difference between the two treatments in the median time taken for the eggs to hatch (measured from the mid-point of the 20-days egg laying period that was provided in the lab.) (Mann-Whitney $U=7963.5, P>0.05$ ). In fact, the median time taken for the eggs to hatch was identical in the two treatments (Treatment A: 332 days, range 327-339, $\mathrm{n}=149$; Treatment B 332 days, range $327-340, \mathrm{n}=108$ ). The hatching success of eggs in both treatments was high (98\% and $91 \%$ respectively). The few un-hatched eggs in both treatments were all dead and were covered with mould.

In addition to the eggs maintained in petri dishes (above), hatching data was recorded from eggs laid in the females' rearing cages in a variety of oviposition media from mid-August 2014 to April 2015 (the precise point at which these were laid is unclear because the oviposition substrata were left in the rearing cages throughout this period). Within the terraria containing the females from Branscombe, 84 eggs laid within card hatched from 3rd to 30 th June 2015 , with most eggs hatching by 15 th June. The hatching success for these eggs was $94 \%$ (79 out of 84 eggs). Within the same cage, un-counted eggs which had been laid in cotton-wool and within driftwood showed a peak of hatching on 29th June 2015. In a cage of females from Marloes sands (which were adult from the end of July 2014), 54 eggs laid in a cotton-wool pad hatched from 17th to 22nd July 2015, with most eggs hatching by 19th July (the hatching success for these eggs was $91 \%$ ).

None of the seven adult virgin females laid any eggs during the 3 month trial. It was therefore not possible to determine if un-fertilised eggs would hatch. 


\section{Discussion}

\section{The number of nymphal instars}

The number of nymphal instars was found to vary both within and between the sexes (mode: 10, range 10-11 in males; mode: 11 , range 11-13 in females). Intraspecific variation in the number of instars is known to occur in a wide range of insects, including the Orthoptera, and has been linked with numerous factors including temperature, humidity, photoperiod, food quality and quantity, rearing density and sex (Masaki and Walker 1987; Esperk et al. 2007). Taniguchi and Tomioka (2003), for example, found that the number of instars in the cricket Modicogryllus siamensis ranged from 7 to 14 depending upon the photoperiod. In grasshoppers such as Chorthippus brunneus and Omocestus viridulis, females have sometimes been found to have an extra instar that is not found in the males (Hassall and Grayson 1987; Berner and Blanckenhorn 2006). Head width in adult $P$. vicentae was significantly greater in adult females than in adult males, which could be a result of the higher number of instars. The sexual dimorphism in head width in this species is in the opposite direction to that documented in gryllid crickets in which males aggressively compete for access to females (Judge and Bonanno 2008). In the present study, adult males did not show any signs of aggression towards one another in captivity.

The lower number of instars typically found in males in the present study could reflect selection on males favouring protandry (i.e. development to adulthood prior to females). This occurs in numerous insects, including orthopterans such as the Wartbiter, Decticus verrucivorus (Wedell 1992), and appears to be a sexually selected trait, giving the protandrous males an advantage in gaining copulations and fertilisations prior to their competitors (Wedell 1992). In the present study, there was some evidence of protandry in nymphs collected from the field and raised to adulthood in the laboratory: in one cohort, the first males reached adulthood 1 week before the first females. This did not, however, occur in another cohort. The occurrence of protandry in this species could be confirmed by regular pitfall trap surveys throughout June, July and August at the same site.

\section{Nymphal instars present in the field at different times of the year}

The presence of many first instar nymphs in the late July and early August field surveys in this study suggests that this is when the majority of eggs hatch. The presence of some older (up to III and IVth instar) nymphs in late July, however, indicates that hatching begins in June at both sites. This is consistent with the peak of hatching in the lab. in June and July in the present study (see below). Sutton (1999) and Livory et al. (2000) reported the occurrence of first instar nymphs from July to September in populations of $P$. vicentae in Branscombe, Devon and Champeaux, Normandy respectively.

The late October and February surveys indicated that the majority of individuals at both sites overwinter at instar VII. There was variation in this, however: some individuals, which could have been from late-hatching eggs, were at earlier instars, even in the mid-April samples (e.g. one at instar III). It would be interesting to determine if such small overwintering nymphs develop to adulthood later than the larger nymphs or whether they miss out instars and develop as smaller adults in order to reach maturity at the same time as larger nymphs. Overwintering at the nymphal stage is found in a variety of other cricket species (Masaki and Walker 1987; Masaki 1996). In Nemobius sylvestris, Brown (1978) described this resting phase as a period of quiescence rather than true diapause, noting that when exposed to higher temperatures at intervals through the winter, nymphs resumed moulting immediately. In the present study, nymphs in the February hand searches were still relatively active even at $7{ }^{\circ} \mathrm{C}$ and were capable of hopping.

The field surveys suggest that moulting probably resumes in April (most individuals were at instar VIII in mid-April at Marloes Sands). The resumption of moulting is likely to be temperature dependent, although the precise threshold temperature needed to trigger moulting was not examined in the present study. By late May, most individuals appear to reach the Xth or XIth instar (typically 1 to 2 moults before adulthood). The ovipositor first becomes visible from above in females 2 moults before adulthood, as it does in Acheta domesticus (Bate 1971). Data from field surveys and individuals reared from field-collected nymphs in the present study suggests that nymphs typically become adult from late June to mid-August. Previous studies of this species have recorded adults from either July (Livory et al. 2000) or early August (Sutton 1999). Again, the timing of the final moult is likely to be temperature dependent and could vary depending upon the latitude and climatic conditions in the spring: in Guernsey, for example, a very high proportion of adults were found in surveys on 30th June (T. Bourgaize, personal communication).

\section{The adult life-span of males and females}

In the field, adults of both sexes were still found in the late October surveys in the present study, but none were found in the February, March, April or May surveys. In the lab., there was a significant difference in the adult lifespan of the sexes: males died by the end of November, while $35 \%$ of 
females survived until March and one survived until July (i.e. survived for approximately 1 year as an adult). This fits with Livory et al. (2000), who reported that in captivity, the one adult male died by November, while adult females survived until April. Timmins (1994b) reported finding an adult female $P$. vicentae at Chesil Beach, Dorset in mid-April and field observations of $P$. squamiger (which has a Mediterranean distribution) also indicate that adults can still be found in April (Dusoulier 2017). Although no adults were found in spring surveys at either Branscombe or Marloes Sands in the present study, pitfall trapping from March to April at Spur Point in Guernsey recently revealed the presence of 13 adult female $P$. vicentae and 2 adult males (together with VII/VIIIth instar nymphs, Vahed and Bourgaize 2019). The more southerly, milder climate of Guernsey might account for this difference.

Gender differences in adult lifespan favouring females have been reported in a variety of taxa (reviewed in Austad and Fischer 2016), although there are many exceptions. Nowosielski and Patton (1965), for example, found no significant difference in adult survival in captivity between the sexes in House crickets, Acheta domesticus. A wide variety of factors have been put forward to account for gender differences in adult survival, including a difference between the sexes in the intensity of sexual selection and vulnerability to environmental factors (Austad and Fischer 2016).

\section{The adult sex ratio}

While the adult sex ratio of lab. reared individuals did not differ from unity, that of individuals caught by pitfall trapping at Branscombe in late July was significantly femalebiased ( $80 \%$ female). A female-biased adult sex ratio has been reported in this species in numerous previous surveys (Kirby 1995; Timmins 1994a, 1996; Sutton 1999; Livory et al. 2000; Hudson 2006). For example, in June 2018, 68\% of adults $(\mathrm{n}=165)$ at a site in Guernsey were female ( $\mathrm{T}$. Bourgaize, personal communication); in early September $2016,86 \%$ of adults $(n=116)$ were female at Chesil beach, Dorset (Poston-Saynor 2016) and in October 2010, 69\% of adults $(n=77)$ were female at Branscombe, Devon (B. Laney and D. Shute, personal communication). Data for early August at the Marloes sands site in the present study, however, were an exception in that a significantly male-biased sex ratio was found. This was driven by just one pitfall trap which contained an unusually large number of males. This could suggest that at certain times of year males may be aggregated. At all stages in captivity, $P$. vicentae individuals seem to have gregarious tendencies and will rest together in groups during the day.

While the shorter lifespan of males could contribute to the typical female-biased sex ratios found in the field in the autumn, it would obviously not account for female biased sex ratios in June or July when the adults are young. Rebrina and Brigić (2017) reported female-biased pitfall trap catches in another mogoplistine cricket, Mogoplistes brunneus and proposed that this might be due to females having a greater need to forage for food in order to develop eggs.

\section{Egg development}

Eggs laid in August in captivity in the present study showed no visible embryonic development until late spring (May) and hatched the following July. These eggs had been cooled then exposed to an increase in temperature to $12{ }^{\circ} \mathrm{C}, 15{ }^{\circ} \mathrm{C}$ and $16{ }^{\circ} \mathrm{C}$ in March, April and May, respectively. This strongly suggests that a period of cooling (and/or a subsequent temperature rise) is necessary before the eggs begin embryonic development, although it should be noted that a control group with no period of cooling was not included in the present study. Diapause at either the very early embryo stage or the whole embryo stage (or even at both stages, in some cases) is found in numerous ensiferan species in temperate climates (Masaki and Walker 1987; Hartley and Warne 1972). In some species there is geographical variation in the occurrence of diapause at the eggs stage (Masaki and Walker 1987). In British populations of the Wood cricket, Nemobius sylevestris, for example, Brown (1978) provided evidence that the diapause is obligatory; a period of cooling is necessary before eggs will hatch. In some French populations of the same species, however, some females produce eggs that develop without diapause (Brown 1978). It might be predicted that populations of $P$. vicentae in the southern part of their range (e.g. on the Canary Islands) might similarly lack an egg diapause.

There was no difference in the time taken to hatch between eggs maintained over winter at either 4 or $11{ }^{\circ} \mathrm{C}$ and both showed a high percentage hatch (of over $90 \%$ ). Similar experiments using other cricket species, such as Teleogryllus commodus, however, have found an effect of the temperature of the cool period on the termination of diapause (Masaki and Walker 1987). Eggs in both overwinter temperature treatments in the present study hatched after a median of 332 days, from 2nd to 15th July. Other batches of eggs in the present study hatched from early June to late July. This date range is consistent with the occurrence of first instar nymphs in the field. It would be interesting to examine whether $P$. vicentae females that have successfully overwintered as adults will lay fertile eggs and, if so, whether they would develop straight through to hatch in June or July without a diapause. Brown (1978) reported that in N. sylvestris, eggs laid by females that had overwintered as adults were not viable. An additional aim of the present study was to determine whether un-fertilised eggs will hatch in $P$. vicentae. Because none of the virgin females laid any eggs, it was not possible to 
examine this. This fact in itself, however, suggests that the individuals examined were not capable of parthenogenetic reproduction.

\section{Survival in a dynamic, shifting habitat}

Observations in the present study suggest ways in which $P$. vicentae might survive winter storms in both the nymphal and egg stages. At the Marloes sands site, during an incoming tide with high wind and high surf, approximately one hundred $P$. vicentae nymphs were seen all walking rapidly away from the sea and scaling the rocks up to $6 \mathrm{~m}$ above the beach. This mass migration of individual $P$. vicentae away from advancing waves has also been observed on the island of Sark (P. Brown, personal communication). The tendency of female $P$. vicentae to lay eggs in driftwood demonstrated in this study could represent a further adaptation to inundation by sea water during storms. Observations in previous studies indicated that females oviposited in sand (Paul 1987; Benton 2012), but individuals in the present study showed a clear preference for driftwood and would also oviposit in other fibrous media such as card and cotton-wool. Driftwood was common in the scaly cricket habitat at both field sites, both in terms of larger pieces on top of the shingle and smaller fragments within. Fragments of seaweed, such as Kelp (Laminaria spp.) were also present, but these were very hard when dry and are unlikely to be suitable for oviposition.

In the driftwood medium, overwintering eggs may be resistant to soaking by sea water and, furthermore, might also be able to raft to new locations. That eggs show no visible embryonic development until after the winter and take nearly a year to hatch further increases the possibility that eggs would have time to be washed to new locations and that long range dispersal might be even possible. Warne and Hartley (1975) similarly proposed that eggs of the bushcricket Conocephalus dorsalis (Orthoptera: Tettigoniidae), which are laid in the stems of rushes and sedges, may be distributed by rafting on the sea. They demonstrated that $C$. dorsalis eggs can survive exposure to sea water for several months and noted that while sea water caused the eggs to loose water, development was resumed after the eggs were transferred to fresh water. Whether or not the eggs of $P$. vicentae can similarly survive prolonged periods of exposure to sea water has not yet been tested, however. Long range dispersal of organisms via driftwood is a well-documented phenomenon (Thiel and Gutow 2005; Wildish 2012), but most studies have focussed on dispersal of adult or larval organisms rather than eggs in the wood. It is possible that dispersal of eggs via driftwood could account for the presence of members of this flightless genus on volcanic islands such as the Canary Islands and Madeira and on numerous Mediterranean islands.
Implications of the results to the conservation of $P$. vicentae

One of the reasons for the current IUCN classification of P. vicentae as Vulnerable (Hochkirch et al. 2016a, b) is that the populations are assumed to be severely fragmented, with little chance of gene flow between them. The possibility that the species may be able to disperse by rafting at the egg stage raises the question of whether there may in fact be genetic connectivity between apparently isolated populations of this species. This also raises the question of whether $P$. vicentae may actually be expanding in range. The number of known sites for this species have increased over the last two decades (reviewed in Sutton 1999; Benton 2012). The populations at Branscombe and Marloes sands, for example, were only discovered in 1998 and 1999, respectively.

Potential threats to $P$. vicentae populations, on the other hand, include an increase in the frequency of severe storms and rising sea levels, associated with climate change (Sutton 2015; Sutton et al. 2017; Hochkirch et al. 2016a, b). First-hand evidence of this was observed in the present study in terms of the effects of the severe storm surge in the winter of 2013, which was the largest to hit the UK in the last 60 years (Spencer et al. 2015). This event removed a substantial amount of shingle from Branscombe beach and there was evidence that over-wintering eggs were affected (no newly hatched nymphs were found in surveys the following July and no overwintered nymphs were found in April or May 2015). At Marloes Sands, a series of storms in autumn/ winter 2015 flattened out a bank of cobbles at one of the sampling sites, leading to a dramatic decrease in the number of $P$. vicentae found during hand-searches and the need to change the sampling location. A further potential threat revealed by the present study is the collection of driftwood and the construction of driftwood bonfires, which could destroy eggs of $P$. vicentae laid within. Evidence of these activities was observed repeatedly at both Marloes Sands and Branscombe beach and it is recommended that notices to discourage these practices should be installed at both sites.

The semivoltine life cycle confirmed by this study also has conservation implications. With such a life cycle, it is probable that individuals from 'even' and 'odd' years at the same site (e.g. represented in winter by nymphs, on the one hand, and eggs, on the other) effectively represent independent populations, with no apparent opportunity for gene flow between them. There is some evidence for this in odonates with semivoltine life cycles (Phillips and Swanson 2018). This has implications for interpreting surveys of the species. It is possible, for example, that some sites may only consist of either 'odd' or 'even' year populations and from August, adults might be present, while small nymphs may be entirely absent, or vice versa. 


\section{Conclusion}

Through field sampling of developmental stages at various points throughout the year, together with lab. rearing of individuals, this study has confirmed that the Scaly Cricket has a semivoltine life cycle, spanning two full years from egg to adult, with some adult females (35\% in the lab.) possibly surviving well into a third year. It was found that this species over-winters in both the egg stage (with an early embryonic diapause) and as mid-stage nymphs (typically VIIth instar). The life cycle is therefore almost identical to that of the Wood cricket, $N$. sylvestris (although with a greater number of instars, Gabbutt 1959; Brown 1978). The discovery that females will lay eggs in driftwood, together with the time taken for eggs to hatch (almost 1 year), raises the intriguing possibility that the species may be able to disperse via rafting at the egg stage.

Acknowledgements I thank the following people for their contribution to this study: Peter Sutton, Jon Hudson, Rose Poston-Saynor, Peter Brown, Trevor Bourgaize, Brian Laney and Adrian Colston for discussion and for supplying useful information; Kate Bellis and Gabriel Vahed for field assistance; Sebastian Dixson for assistance with assessing egg development and Alex Hyde for photography and permission to use his photographs. I am also grateful to two anonymous referees for their constructive comments and suggestions which have improved the manuscript.

Funding This study was part-funded by the University of Derby.

\section{Compliance with ethical standards}

Conflict of interest The author declares that he has no conflict of interest.

Informed consent This article does not contain any studies involving Human participants.

Research involving animals The study species is included on the IUCN European Red List as 'Vulnerable', however, the collection of this species is not currently subject to restriction by law in the UK and does not require collecting permits. Nevertheless, permission for pitfall trapping was obtained from the National Trust and/or Natural England. All applicable guidelines for the use of animals in research were followed and every attempt was made not to cause harm or undue stress to individuals. The crickets were caught live and pitfall traps were only left overnight to minimise the risk of mortality. The trapped invertebrates were generally released live, apart from a small number of scaly crickets that were removed in order to study oviposition and development in the lab. The number removed from each site at any one time was kept to a minimum and it is highly unlikely that this would have had a negative effect on the population.

Open Access This article is distributed under the terms of the Creative Commons Attribution 4.0 International License (http://creativeco mmons.org/licenses/by/4.0/), which permits unrestricted use, distribution, and reproduction in any medium, provided you give appropriate credit to the original author(s) and the source, provide a link to the Creative Commons license, and indicate if changes were made.

\section{References}

Austad SN, Fischer KE (2016) Sex differences in lifespan. Cell Metab 23:1022-1033

Bate J (1971) Life history of Acheta domesticus (Insecta, Orthoptera, Gryllidae). Pedobiologia 11:159-172

Benton T (2012) Grasshoppers and crickets. The New Naturalists Library, Collins

Berner D, Blanckenhorn W (2006) Grasshopper ontogeny in relation to time constraints: adaptive divergence and stasis. J Anim Ecol $75: 130-139$

Brookes HM (1952) The morphological development of the embryo of Gryllus commodus Walker (Orthoptera: Gryllidae). Trans R Soc S Aust 75:150-159

Brown VK (1978) Variations in voltinism and diapause intensity in Nemobius sylvestris (Bosc.) (Orthoptera: Gryllidae). J Nat Hist 12:461-472

Dusoulier F (2017) Redécouverte du Grillon maritime Pseudomogoplistes squamiger (Fischer, 1853) (Orthoptera: Mogoplistidae) sur le territoire du Parc national de Port-Cros (département du Var, France) et premiers éléments de recherches sur son écologie. Sci Rep Port-Cros natl Park 31:81-103

Espadaler X, Olmo-Vidal JM (2011) The myrmecophilic cricket Myrmecophilus in Spain (Orthoptera, Myrmecophilidae). Sociobiology $57: 321-328$

Esperk T, Tammaru T, Nylin S (2007) Intraspecific variability in number of larval instars in insects. J Econ Entomol 100:627-645

Gabbutt PD (1959) The bionomics of the wood cricket Nemobius sylestris (Orthoptera: Gryllidae). J Anim Ecol 28:15-42

Gardiner T (2009) Distribution of the scaly cricket Pseudomogoplistes vicentae Gorochov (Orth: Gryllidae) in relation to public access at Chesil Beach in Dorset. Entomologist's Rec J Var 121:292-295

Gorochov AV (1996) A new species of Pseudomogoplistes from Morocco and Portugal (Orthoptera: Mogoplistidae). Zoosyst Ross 4(2):292

Groepler W (1981) Das experiment: embryonalentwicklung Wanderheuschrecke. Biol unserer Zeit 11:91-94

Gwynne DT (2001) Katydids and bushcrickets: reproductive behaviour and evolution of the Tettigoniidae. Cornell University Press, Ithaca and London

Hartley JC (1990) Egg biology of the Tettigoniidae. In: Bailey WJ, Rentz DCF (eds) The Tettigoniidae: biology, systematics and evolution. Crawford House Press, Bathurst, pp 41-70

Hartley JC, Warne AC (1972) The developmental biology of the egg stage of Western European Tettigoniidae (Orthoptera). J Zool Lond 168:267-298

Hassall M, Grayson FWL (1987) The occurrence of an additional instar in the development of Chorthippus brunneus (Orthoptera: Gomphocerinae). J Nat Hist 21:329-337

Hochkirch A, Nieto A, García Criado M et al (2016a) European red list of grasshoppers, crickets and bush-crickets. Publications Office of the European Union, Luxembourg

Hochkirch A, Oromi P, Braud Y, Tim G, Vahed K, Ferreira S, Presa JJ, Roesti C, Rutschmann F, Dusoulier F, Zuna-Kratky T, Monnerat C, Fontana P (2016b). Pseudomogoplistes vicentae. The IUCN Red List of Threatened Species 2016: e.T68460220A74521891

Hudson J (2006) Scaly cricket (P. vicentae) on Marloes coast, Pembrokeshire. Countryside Council for Wales Report 766

Ismail S, Fuzeau-Braesch S (1976) Programmation de la diapause chez Gryllus campestris. J Insect Physiol 22:133-139 
Judge KA, Bonanno VL (2008) Male weaponry in a fighting cricket. PLoS ONE 3(12):e3980. https://doi.org/10.1371/journ al.pone.0003980

Kirby P (1995) Lyme Bay environmental study. Volume 14. Terrestrial ecology: invertebrates of Chesil beach. Ambois Environmental Consultants Ltd. For the Kerr McGee Group

Kleukers R, Ode B, Willemse L (2018) First record of the Atlantic Beach-Cricket Pseudomogoplistes vicentae on the Spanish Mainland. Articulata 33:131-134

Livory A, Coulomb R, Morère J-J (2000) Nouvelles observations sur le grillon maritime Pseudomogoplistes vicentae septentrionalis. L'Argiope 28:47-63

Love RE, Walker TJ (1979) Systematics and acoustic behaviour of scaly crickets (orthoptera: Gryllidae: Mogoplistinae) of eastern United States. Trans Amer Ent Soc 105:1-66

Masaki S (1996) Geographical variation of life cycle in crickets (Ensifera: Grylloidea). Eur J Entomol 93:281-302

Masaki S, Walker TJ (1987) Cricket life cycles. In: Hecht MK, Wallace B, Prance GT (eds) Evolutionary biology, vol 21. Plenum Publishing Corporation, New York, pp 349-423

Mills SL (2012) Conservation of wildlife populations: demography, genetics and management, 2nd edn. Wiley-Blackwell, Oxford

Morère J-J, Livory A (1999) Le grillon maritime de la Manche: Une espèce nouvelle pour la France. L'Argiope 23:29-37

Nowosielski JW, Patton RL (1965) Life-tables for the house cricket, Acheta domesticus $\mathrm{L}$., and the effect of intra-specific factors on longevity. J Insect Physiol 11:201-209

Paul J (1987) Conocephalus discolor (Thunberg) (Orthoptera) new to Wiltshire and other notes on British Orthoptera in 1985. Entomologist's Rec J Var 99:107-109

Pearce-Kelly P, Croft P, Atkin P, Clarke D (1997) An ex situ breeding programme for the endangered UK population of the field cricket Gryllus campestris. Mem Mus Vic 56:587-589

Phillips P, Swanson BJ (2018) A genetic analysis of dragonfly population structure. Ecol Evol 8:7206-7215

Pickard BC (1956) Mogoplistes squamiger (Fischer), Conocephalus discolor (Thun.) and Chorthippus vagans (Eversmann) (Orth. Saltatoria) in Dorset. Entomol Mon Mag 92:6

Poston-Saynor R (2016) An investigation of the scaly cricket (Pseudomogoplistes vicentae) population at Chesil Beach, Dorset. MSc Dissertation, University of Derby

Rebrina F, Brigić A (2017) Morphometric variability and life history traits of the rare Paramogoplistes novaki in comparison to Mogoplistes brunneus (Orthoptera: Mogoplistidae). Ann Soc Entom France 53:313-323

Sahnoun AM, Doumandji SE, Desutter-Grancolas L (2010) A checklist of Ensifera from Algeria (Insecta: Orthoptera). Zootaxa 2432:1-44
Schneider CA, Rasband WS, Eliceiri KW (2012) NIH Image to ImageJ: 25 years of image analysis. Nat Methods 9:671-675

Spencer T, Brooks SM, Evans BR, Tempest JA, Möller I (2015) Southern North Sea storm surge event of 5 December 2013: Water levels, waves and coastal impacts. Earth Sci Rev 146:120-145

Sutton PG (1999) The scaly cricket in Britain: a complete history from discovery to citizenship. Br Wildl 10:145-151

Sutton P G (2015) A review of the Orthoptera (grasshoppers and crickets) and allied species of Great Britain. Orthoptera, Dictyoptera, Dermaptera, Phasmida. Species Status No. 21. Natural England Commissioned Report NECR 187

Sutton P, Beckmann BC, Nelson B (2017) The current status of Orthopteroid insects in Britain and Ireland. Atropos 59:6-35

Taniguchi N, Tomioka K (2003) Duration of development and number of nymphal instars are differentially regulated by photoperiod in the cricket Modicogryllus siamensis (Orthoptera: Gryllidae). Eur J Entomol 100:275-281

Thiel M, Gutow L (2005) The ecology of rafting in the marine environment. I. The floating substrata. Oceanogr Mar Biol Annu Rev 42:181-264

Timmins CJ (1994a) The population size of Pseudomogoplistes squamiger Fischer (Orth. Gryllidae) on Chesil Beach, Dorset. Entomol Mon Mag 130:66

Timmins CJ (1994b) The life cycle of Pseudomogoplistes squamiger Fischer (Orth. Gryllidae). Entomol Mon Mag 130:218

Timmins CJ (1996) Project to assess the distribution of Pseudomogoplistes squamiger (Fischer) in Britain. Unpublished report for English Nature

Vahed K, Bourgaize T (2019) Overwintered adult male Scaly crickets, Pseudomogoplistes vicentae Gorochov (Orthoptera: Gryllidae), found in Guernsey in March/April. Br J Ent Nat Hist (in press)

Warne AC, Hartley JC (1975) The distribution and dispersal of Conocephalus dorsalis (Latrielle) (Tettigoniidae) in the British Isles. Entomol Gaz 26:127-132

Wedell N (1992) Protandry and mate assessment in the wartbiter Decticus verrucivorus (Orthoptera: Tettigoniidae). Behav Ecol Sociobiol 31:301-308

Wildish DJ (2012) Long distance dispersal and evolution of talitrids (Crustacea: Amphipoda: Talitidae) in the northeast Atlantic islands. J Nat Hist 46:2329-2348

Publisher's Note Springer Nature remains neutral with regard to jurisdictional claims in published maps and institutional affiliations. 